\title{
PROJECT SUCCESS IN SLOVENIAN COMPANIES
}

\section{PALCIC, I[ztok]; BUCHMEISTER, B[orut] \& BREZOCNIK, M[iran]}

\begin{abstract}
This paper has a two-fold purpose. First we want to introduce the project success concept in general. The concept of project success evolved in the last 50 years. The critical success factors for measuring project success have also changed. All these facts mean that it is very difficult to make unbiased decision on whether the project has been successful or not. In the second part of the paper we present the results of the survey research that we conducted among Slovenian companies in the years 2010 and 2011. We were keen to find out how are they prepared to implement projects in their environment. In the research we have focused on several project types (area, aim, novelty, importance) in various business environments (industry, size) and determined the success level of projects regarding different factors. This paper focuses mostly on project success of implementing projects in general.
\end{abstract}

Keywords: project, project success, project type, company project-orientation

\section{INTRODUCTION}

The word "success" has different meaning for each person. It is extremely context related and, therefore, hard to measure [1]. The best way to do it is to assign goals and analyze the extent, to which the goals have been achieved. It is even harder to measure the success of projects. Projects are complex, surrounded by uncertainty, involve many individuals and other stakeholders, demand financial investments, use resources and include a set of sometimes versatile goals. To measure project success is even more difficult than measuring success of individual person. We need a set of specific criteria to measure its success and above that a compromise between all project stakeholders. Extremely large number of methodologies for measuring project success has been developed in the last 50 years and they are still developing.

This paper focuses on measuring project success using the work Shenhar et al. [2]. They determined that the expected project values should be identified at a project's onset so that everyone was aware of them during the project. Their study identified three clusters of success: a) meeting design goals, b) impact on the customer, and c) benefits to the organization. We have developed six project success criteria based on Shenhar's work and measured project success in Slovenian companies. Based on extensive survey, conducted in 2010 and 2011 among over 1000 individuals that deal with projects, we present several interesting insights of project success depending on company size, project type, company project-orientation and other factors. In the end we propose future research plans based on the results of our survey.

\section{PROJECT SUCCESS}

Early mechanistic definitions of project management focused on the variables of time, cost, and scope (performance / quality) - otherwise known as the "iron triangle" [3]. The "iron triangle" of so-called "triple constraint" was once the standard by which project performance was measured (Fig. 1).

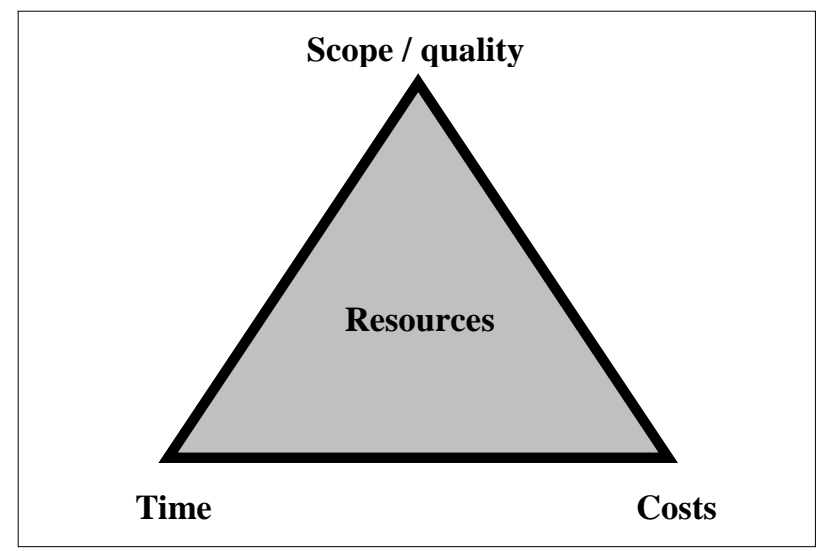

Fig. 1. Iron triangle of project success

If the project fulfills these three criteria, it is said to be efficient. The relationship between all three criteria emphasizes the fact that we have to find an appropriate balance between performance, time and costs. It is practically impossible to improve one of these criteria without influencing the other two. Efficiency looks at maximizing output for a given level of input, and effectiveness means achieving the goals or objectives; both are goal-oriented practices related to achieving success [4].

Later, a fourth criterion has been added: client acceptance. It is obvious that projects are developed with the purpose to satisfy customers' needs. If client acceptance is a key variable, then we must ask whether the completed project is acceptable to the customer for whom it was intended [5]. Besides efficiency we must consider also project effectiveness. Efficiency is widely known as doing things right, and effectiveness as doing the right things (Fig. 2)

Recent definitions of project management are more inclusive and emphasize the importance of working with stakeholders to define needs, expectations, and project tasks. These definitions describe project management as involving cultural, structural, practical, and interpersonal aspects [6]. Project management is about managing people to deliver results, not managing work [7]. 


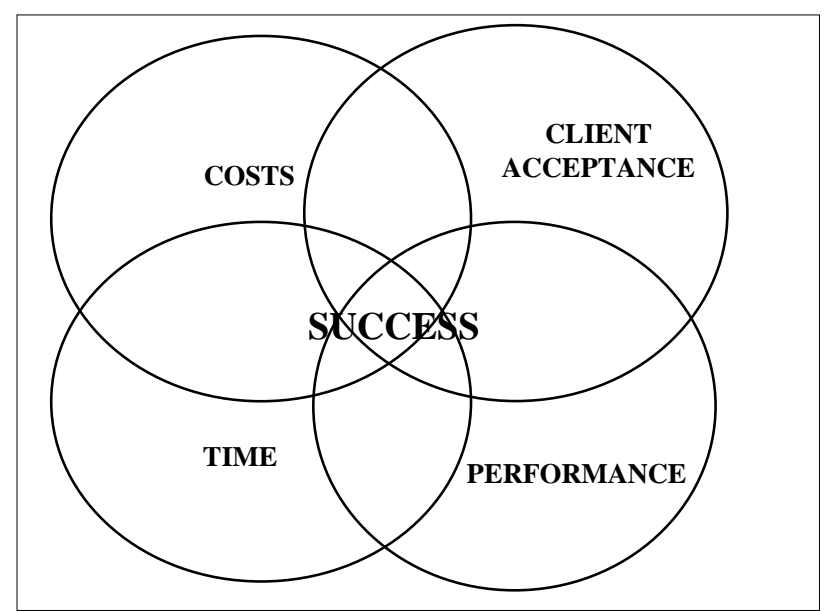

Fig. 2. The new Quadruple constraint [4]

Judgev and Müller [1] in their paper analyzed the project success concept, made an extensive literature review and discussed that we have to consider two types of project success:

1. Project management success, being measured against the traditional gauges of performance (i.e., time, cost, and quality), and

2. Project success, being measured against the overall objectives of the project.

Based on that, they argue that project success evolved in last 50 years through 4 periods. We saw a slow but gradual understanding that project management success should be assessed with input from stakeholders, and it should be assessed beyond the project phases.

Period 1 was Project Implementation and Handover (1960s-1980s). During Period 1, simple metrics such as time, cost, and specifications were used to rate project success because they are easy to use and within the realm of the project organization. Project managers focused on getting a project done, making sure it worked, and getting it out the door.

Period 2 was Critical Success Factors Lists (1980s1990s). Kerzner defined CSFs as the few elements where »things must go right [8]. CSFs are the elements required to create an environment where projects are managed consistently with excellence $\ll$. The literature focused on the importance of stakeholder satisfaction as an indicator of project success.

Period 3 was Critical Success Factors Frameworks (1990s-2000s). We saw some significant contributions to the literature with the emergence of integrated frameworks on project success. Most of the publications on the topic addressed the concept that success was stakeholder-dependent and that success involved the interactions between the internal and recipient organization.

Period 4 is Strategic Project Management (21st Century). We understand that project success dimensions include benefits to the organization and preparing for the future (e.g., innovating, and developing core competencies). Today's approach shifts considerable responsibility for project success to the project owner. It reconfirms the need for the owner to empower the project manager and be willing to renegotiate success criteria over the project life cycle.

\section{RESEARCH METHODOLOGY}

Research methodology used in our paper is survey research. We conducted an on-line survey among Slovenian companies in the years 2010 and 2011. We have sent a questionnaire to approximately 1.300 individuals who deal with projects in different roles (mostly as project managers). We received 265 responses, meaning $24 \%$ response rate. For the purpose of this paper we have used 212 complete responses. We will present the results of our research using descriptive statistics.

The main focus of our research was two-fold. Besides analyzing success level of projects conducted in Slovenian companies and other organizations we also wanted to determine how they are prepared to implement projects in their environment. The key issue was the relationship between organizational and project readiness to execute projects and project success [9]. This paper focuses mostly on success of implementing projects in general.

As we have already mentioned, we have used Shenhar's [2] methodology to measure project success. Therefore we have developed six most important project success criteria:

1. Project performance - quality of project results was adequate, customers were satisfied.

2. Budget - project budget was not exceeded at the project completion.

3. Schedule - project schedule was not exceeded at the project completion.

4. User satisfaction - project users and other stakeholders are satisfied with project results. It focuses on the customer with questions like: were the customer and users satisfied, were the project deliverables delivered with the proper quality, were the deliverables used. This goes beyond the traditional view of "meet the specification".

5. Impact on business - projects must increase competitive advantage, bring in much needed revenues, achieve much needed cost savings, and add value to the company in the long run.

6. Building for future - what is a three to five year impact of the project on the company? Was new infrastructure (facilities, networks, etc.) built ahead of time, were employees given the opportunity to acquire new skills that could be used in the future. These are the questions for this period. Is the company positioned to address new products or new markets after this project [10]?

We have used Likert scale for the respondents to evaluate each project success criteria:

1. very low level of project success,

2. low level of project success,

3. under average level of project success,

4. above average level of project success,

5. high level of project success,

6. very high level of project success. 


\section{RESULTS}

First we have analysed the relationship between company size and project success. We have measured company size based on only one criterion - number of employees (Fig. 3).

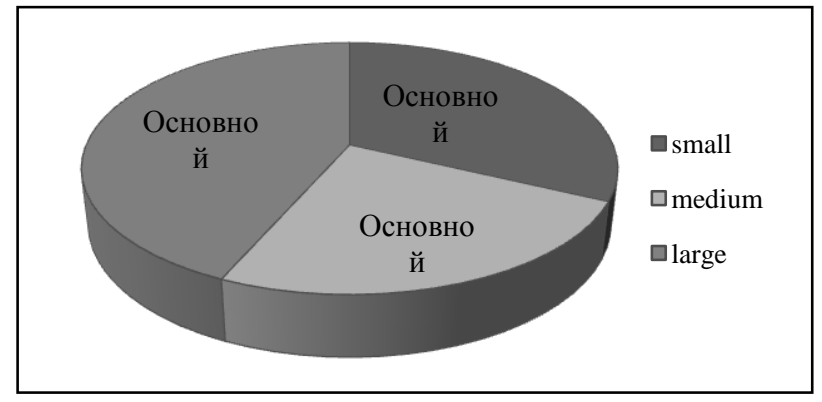

Fig. 3. Percentage of companies based on company size

Table 1 presents project success criteria based on the company size. We will use this table for several analyses. First, we will neglect the company size and focus only on individual project success criteria. Looking at the numbers resembling the level of project success based on six criteria, one would conclude that the numbers are quite high. They are mostly between 4 and 5 based on the 6 -level scale. We have already pointed out that the project is efficient when it fulfills the first three criteria (performance, budget and schedule).

For the project to be completely efficient it should mean that it received the highest grade for all three criteria. When we analyzed all 197 responses we found out that only 15 projects got the perfect score on the performance / budget / schedule criteria $(7.1 \%$ of all projects). This means that all other 205 projects were at their completion behind schedule, over the budget or lacked in their performance.

If we include also the other three criteria and analyze the overall project success, only 7 projects got a perfect score (3.3\% of all projects). If we lower our standards and proclaim as a success each project with the average score of at least 5.5, the percentage of successful projects rises up to $20 \%$. If we further lower the average score for successful project to 5.0, than $36 \%$ of projects fall into this category (the other criteria was that no single project success criteria is under score 3 ).

If we analyze individual project success criteria, we were surprised to find out that the worst project success criteria was project schedule. More than half of projects were at their completion significantly behind planned schedule. Only around $20 \%$ of all projects were on time. The second worst project success criterion was impact on business. Around $25 \%$ of all projects had a negative financial impact on the company.

\begin{tabular}{|l|c|c|c|c|}
\hline Company size & small & medium & large & Sum \\
\hline Project performance & 5,07 & 4,81 & 4,61 & 4,83 \\
\hline Project budget & 4,87 & 4,44 & 4,62 & 4,64 \\
\hline Project schedule & 4,37 & 4,31 & 4,11 & 4,26 \\
\hline User satisfaction & 4,99 & 4,71 & 4,68 & 4,79 \\
\hline Impact on business & 4,58 & 4,40 & 4,29 & 4,43 \\
\hline Building for future & 5,19 & 5,02 & 4,83 & 5,01 \\
\hline
\end{tabular}

Tab. 1. Project success based on six criteria and company size
Table 1 also presents project success based on a company size. The numbers show that there is a slight dependence between company size and project success. We found out that small companies have the highest project success rate, whilst large company the lowest. The results could be surprising. One would expect higher project success rates in large companies as these companies should have been more organized to perform projects. Large companies often implement specific project management methodologies to plan and implement their projects. We could conclude that organizational structures in large companies are often too rigid which can cause problems when implementing projects.

Small companies have specific advantages due to their flexibility and commitment to projects in their usually smaller environment. Obviously these two advantages overcome weaknesses, typical for smaller companies (lack of personnel, knowledge, other resources, acquiring financial resources for the project etc.).

We have classified projects from the survey based on several different types. Table 2 presents project types based on their purpose. The table also presents the percentage of these projects and their average project success score.

\begin{tabular}{|l|c|c|}
\hline \multicolumn{1}{|c|}{ Project type } & $\begin{array}{c}\text { Share } \\
\text { in \% }\end{array}$ & $\begin{array}{c}\text { Project } \\
\text { success }\end{array}$ \\
\hline new product / service development & 41,67 & 4,61 \\
\hline information system introduction & 17,16 & 4,70 \\
\hline business process reengineering & 6,86 & 4,32 \\
\hline new technology development & 3,92 & 4,69 \\
\hline customer relationship management & 3,92 & 4,63 \\
\hline organizational project & 10,29 & 4,56 \\
\hline other & 16,18 & 4,88 \\
\hline
\end{tabular}

Tab. 2. Project success and project type

There are no significant differences in project success level based on the project purpose. The only exceptions are business process reengineering projects that are one of the most complex projects in any environment. Surprisingly high is the project success score for the ICT projects.

The last analysis in this paper deals with project orientation of companies. Measuring project orientation is a very difficult task. In our case we did not use the current project organization for project implementation in the company; instead we have used the following:

»What is the share of project related work - project activities (being unique, non-repeated, constrained with budget, schedule and expected results) - compared to other processes in the company (operations and processes as the core activity of the company)?«

The share of project related work can be measured as the scope of total work, dedicated to implement projects, or to some extent as the share of total company income, generated by projects. With this in mind we have classified companies into four groups:

1. process-oriented company - the share of project related work in the company is between 0 to $30 \%$ of all companies activities, 
2. process-project-oriented company - the share of project related work in the company is between 31 to $50 \%$ of all companies activities,

3. project-process-oriented company - the share of project related work in the company is between 51 to $80 \%$ of all companies activities,

4. project-oriented company - the share of project related work in the company is between 81 to $100 \%$ of all companies activities.

Table 3 presents the share of each company group and the average project success score. Table 4 presents the distribution of small, medium and large companies within each of four company groups.

\begin{tabular}{|c|c|c|}
\hline $\begin{array}{c}\text { Company project } \\
\text { orientation }\end{array}$ & Share in \% & Project success \\
\hline $\begin{array}{c}\text { process-oriented } \\
\text { company }\end{array}$ & 45,75 & 4,47 \\
\hline $\begin{array}{c}\text { process-project-oriented } \\
\text { company }\end{array}$ & 20,28 & 4,70 \\
\hline $\begin{array}{c}\text { project-process-oriented } \\
\text { company }\end{array}$ & 10,38 & 4,77 \\
\hline $\begin{array}{c}\text { project-oriented } \\
\text { company }\end{array}$ & 23,59 & 4,89 \\
\hline
\end{tabular}

Tab. 3. Company project orientation and project success

\begin{tabular}{|c|c|c|c|}
\hline $\begin{array}{c}\text { Company project } \\
\text { orientation }\end{array}$ & $\begin{array}{c}\text { small } \\
\text { company }\end{array}$ & $\begin{array}{c}\text { medium } \\
\text { company }\end{array}$ & $\begin{array}{c}\text { large } \\
\text { company }\end{array}$ \\
\hline $\begin{array}{c}\text { process-oriented } \\
\text { company }\end{array}$ & $18,56 \%$ & $28,87 \%$ & $52,58 \%$ \\
\hline $\begin{array}{c}\text { process-project-oriented } \\
\text { company }\end{array}$ & $30,23 \%$ & $25,58 \%$ & $44,19 \%$ \\
\hline $\begin{array}{c}\text { project-process-oriented } \\
\text { company }\end{array}$ & $36,36 \%$ & $22,73 \%$ & $40,91 \%$ \\
\hline $\begin{array}{c}\text { project-oriented } \\
\text { company }\end{array}$ & $58,00 \%$ & $16,00 \%$ & $26,00 \%$ \\
\hline
\end{tabular}

Tab. 4. Company project orientation and company size

The results show that almost one in four companies in Slovenia are project-oriented. The majority of these companies come from ICT sector, civil engineering, consulting and different engineering sectors. The majority of companies are still process-oriented (almost half). In these environments projects are not daily activities, mostly they have strategic importance, but are not direct source of company's income.

It is also interesting to look at the interdependence between company project orientation and company size. Almost $60 \%$ of companies within project-oriented companies are small. This fact should support our finding that small companies have higher average project success score. We expect a positive correlation between company project orientation, its size and project success level.

\section{CONCLUSION}

As indicated in this paper, project success is a complex and ambiguous concept and it changes over the project and product life cycle. Project managers are more effective at managing projects when [1]:

1. Each project requires specific set of project success factors (criteria).

2. Develop a list of key project stakeholders at the beginning of the project and determine which success category each stakeholder fits into.

3. We must ensure that project success indicators include both efficiency and effectiveness measures over the span of the project/product life cycle and that there are CSFs that address all key stakeholders needs and wants.

4. When setting project success criteria we have to be flexible; there is a good change that we will have to adapt them during project implementation to current project environment.

5. Develop and maintain good relationships and effective communications with key stakeholders, and, in particular, project sponsors because their understanding, involvement, commitment, and appropriate decisions for the project will be essential to achieve project success.

We conclude this paper with the following findings from the survey:

1. Small companies are better organized to implement projects and they have higher average project success level.

2. Projects are implemented for building company's future. Project owners are aware of long-term importance of project results. Projects are mostly of strategic importance for the company and they have impact on core activities of the company.

3. Project-oriented companies have higher average project success score (regardless of company size). But this is not the crucial factor for project success. The crucial factor is company's organizational readiness and project readiness. This will be our future research topic.

\section{REFERENCES}

[1] Judgev, K. \& Müller, R. (2005). A retrospective look at our evolving understanding of project success. Project Management Journal, Vol. 36, No. 4, pp. 19-31, ISSN 8756-9728

[2] Shenhar, A., Dvir, D., Levy, O. \& Maltz, A. (2001). Project Success: A multidimensional strategic concept. Long Range Planning, Vol. 34, No. 6, pp. 699-725, ISSN 0024-6301

[3] Atkinson, R. (1999). Project management: Cost, time, and quality, two best guesses and a phenomenon, its time to accept other success criteria. International Journal of Project Management, Vol. 17, No. 6, pp. 337-342, ISSN 0263-7863

[4] Belout, A. (1998). Effects of human resource management on project effectiveness and success: Toward a new conceptual framework, International Journal of Project Management, Vol. 16, No. 1, pp. 21-26, ISSN 0263-7863

[5] Pinto, J. (2007). Project Management: achieving competitive advantage, Pearson Education, USA

[6] Cleland, D. I. \& Ireland, L. (2002). Project management: Strategic design and implementation, McGraw-Hill, New York, USA

[7] Turner, J. R. (2008). The Handbook of Project-based Management: Leading Strategic Change in Organizations, McGraw-Hill Professional, London, UK

[8] Kerzner, H. (1987). In search of excellence in project management, Journal of Systems Management, Vol. 38, No. 2, pp. 30-40, ISSN 0022-4839

[9] Palcic, I., Buchmeister, B. \& Polajnar, A. (2010). Analysis of Innovation Concepts in Slovenian Manufacturing Companies, Strojniski vestnik - Journal of Mechanical Engineering, Vol. 56, No. 12, pp. 803-810, ISSN 0039-2480

[10] Poli, M. (2006). Project Strategy: The Path to Achieving Competitive Advantage/Value, doctoral dissertation, Hoboken, New Jersey, Stevens Institute of Technology, USA 